\title{
The Establishment of the African Association of Statistical Data Archivists (AASDA)
}

\begin{abstract}
AASDA represents practitioners in survey data curation in Africa and was established to facilitate co-operation among them with regard to the development and use of best practices in the preservation and sharing of survey microdata in the region ${ }^{1}$. This Association was established with the assistance of international organisations promoting optimal management of survey data. These included the International
\end{abstract} Household Survey Network (IHSN) and the International Association for Social Science Information Service and Technology (IASSIST).

\section{Background and Role of the IHSN/ADP}

The IHSN was established in 2004 as a recommendation of the Marrakech Action Plan for Statistics, an international initiative to build statistical capacities in developing countries $^{2}$. The Network aims to improve the quality of survey data in developing countries, and to promote data usage for research and policymaking in these countries. Its membership is comprised of organisations that provide funding and technical support for survey programmes in these countries, and includes among others representatives from the UK's Department for International Development (DFID), PARIS21, the UN Statistics Division and the World Bank. Coordination of the Network is undertaken by the World Bank's Development Data Group (DECDG).

The IHSN has developed a programme of action to counter obstacles to survey data production and utilisation in developing countries. Problems with data curation in these countries include limited funding, and a lack of technical resources and expertise to collect and manage survey microdata. Lack of co-ordination of international programmes designed to support statistical development in these countries has hampered their effectiveness. The IHSN's plan of action includes the co-ordination of donor programmes supporting data curation, and the provision of guidelines and technical tools for optimal survey data management to promote the production of quality data in developing countries. Further plans to assist data management include conducting and maintaining data audits for relevant countries, and establishing regional data archiving organisations for networking to support data curation and data sharing among these countries ${ }^{3}$.
Guidelines and tools designed by the IHSN and other agencies are available via the IHSN website. They deal with the full survey life cycle, from sampling and questionnaire design to data archiving and dissemination. Included is a question bank (the IHSN Q-Bank), a central, XML-based repository for international classifications, and links to international surveys. The website supplies information on data anonymisation as well as open source software for this purpose, and publications on metadata standards for data documentation. Software designed by the IHSN includes the Microdata Management Toolkit for documenting and disseminating data according to international standards. The Network has also designed the National Data Archive (NADA) toolkit, which is an open-source Web application that allows the creation of searchable online data catalogues and data downloading via the $\mathrm{Web}^{4}$.

The IHSN does not provide technical or financial support to countries. The Accelerated Data Programme (ADP) was thus initiated in 2006 to expedite the goals of the IHSN. This project, financed by the World Bank and implemented as a satellite program of the PARIS21 Secretariat at the OECD, provides training and assistance in data curation to National Statistics Offices (NSOs) in developing countries, utilising the tools designed by the IHSN. ${ }^{5}$

\section{The IHSN, IASSIST and Data Management in Africa} In Africa the work of the IHSN/ADP partnership builds on the incremental advances in survey data management fostered by previous statistical capacity building projects of regional and international development agencies. However, the work of the partnership has led to major advances in the curation of national survey microdata in several African countries. The project has the potential to realise the goal of data sharing in the region. The project team have achieved this partly through identifying and co-opting key organisations to assist them in this endeavour.

Important links were made when the IHSN co-ordinator attended a conference of the International Association for Social Science Information Service and Technology (IASSIST) in Montreal, Canada, in 2007. IASSIST represents data professionals working with information 
technology and data services for social science research. The IHSN funded the participation of delegates from several African NSOs at this conference. There the IHSN co-ordinator made contact with staff from DataFirst, a Survey Data Archive and training facility based at the University of Cape Town in South Africa. This meeting led to the IHSN's contracting DataFirst to undertake NADA installations and training in African NSOs from $2008 .^{6}$

The IHSN/ADP/DataFirst team are installing the NADA data cataloguing and dissemination software in African NSOs and providing training on the system. The NSOs in Gambia, Ethiopia, Liberia, Nigeria and Uganda have NADA installations. The National Institute of Statistics in Cameroon is at the testing stage of implementing the system. The Mozambican NSO is also being supported by this project, and aims to have a NADA set up by the end of 20087. The software will soon be installed at NSOs in Ghana, Niger, Senegal and Mali (this includes an installation at the Afristat regional offices) ${ }^{8}$. The Nigerian National Bureau of Statistics is the second African NSO (after Statistics South Africa) to provide public use datasets and this has been accomplished by the implementation of the NADA software. Requests for these datasets have been received from researchers abroad and in Africa, providing evidence of data demand within the region. ${ }^{9}$ A comparison of Web searches conducted in 2007 with a recent (August 2008) search reveals that the technology and training provided by the IHSN/ADP/DataFirst team have served to revitalise the websites of African NSOs involved with the project, which has further promoted data discovery via these sites (NSO websites, 2008).

\section{The Establishment of AASDA}

The IHSN/ADP's links with IASSIST helped the IHSN accomplish their goal of creating a regional organisation to facilitate networking among data curation organisations in Africa. This was initiated when African delegates at IASSIST'S 2007 conference formed an interest group concerned with data management in Africa. Founder members of this group included representatives from NSOs in Cameroon, Ethiopia, Gambia, Mozambique, Niger and Uganda, and DataFirst and the Human Sciences Research Council (South Africa). Forms of collaboration among group members initially involved exchanging ideas on data management in Africa, and discussions regarding ways to collaborate on staff training. The idea for an Association for African data managers was initiated by this group. ${ }^{10}$

The IHSN had identified a growing need among NSOs and other data management organisations in Africa for the establishment of a community of practice to work towards regional co-operation in the preservation and sharing of African survey microdata. Thus, they were amenable to providing financial and logistical support for the establishment of an association of survey data managers in Africa. The IHSN/ADP met with the IASSIST Africa group in Kampala to initiate a meeting of representatives from African NSOs and the two African Survey Data Archives ${ }^{11}$ to establish an association of African microdata managers. IASSIST members and the IHSN/ADP team were willing to provide support for this initiative in the form of technical and professional skills transfer.

The inaugural meeting of AASDA was hosted by the DataFirst Survey Data Archive at the University of Cape Town, South Africa, on 10-12 April, 2008. It was attended by delegates from several African $\mathrm{NSOs}^{12}$, the ADP/ IHSN $^{13}$, IASSIST, UNECA's African Centre for Statistics (ACS), the Uganda Statistical Society (USS), the African Development Bank (AFDB), and Afristat ${ }^{14}$. The meeting was opened by the South African Statistician-General, Pali Lehohla, who discussed the problems involved in archiving survey data in Africa. He expressed concern over the lack of indigenous data preservation organisation in Africa, and bemoaned the fact that often the only extant datasets from some African surveys are currently archived in countries outside of Africa. He felt that AASDA could play a key role in supporting the preservation and reuse of high quality African survey microdata.

The meeting represented the first occasion where data managers in NSOs from Francophone, Lusophone and Anglophone African countries had met to form a collaborative grouping. The meeting revised and adopted a constitution for the Association, and elected office bearers. Data managers from the NSOs exchanged experiences on the use of the IHSN microdata management and dissemination tools, and discussed their future data curation plans. The IHSN/ADP team gave an overview of work done with African NSOs, and reiterated their support for data curation organisations in the region.

Delegates emphasised the need to obtain support for AASDA from the senior management of NSOs to encourage them to become aware of the advantages of sound data curation and to promote data sharing in the region. Members of the Association also stressed the need to cater to all language groups represented, and it was agreed the Association should make all important documentation available in both French and English. Delegates concurred with the IHSN/ADP representative when he spoke of training as the key task of the Association. Among other decisions, it was agreed that AASDA should undertake an audit of the training requirements of data managers and all regional data curation training programmes available in Africa ${ }^{15}$.

The AASDA website has been implemented, with the technical assistance of the IHSN/ADP team. ${ }^{16}$ With technical and financial support from international agencies such as the IHSN/ADP, the Association is mandated to work towards overcoming organisational obstacles to data production and data sharing in the region. They aim to 
advocate for the creation of good metadata for African datasets, based on international standards, and for the incorporation of best practices for the preservation and dissemination of data into their organisational agendas. Members receiving training in the use of data curation tools can play a mentoring role on the continent, providing further training, nationally and regionally.

The creation of an Association of Survey Data Archivists in Africa can be seen as a step towards formalizing data sharing on the continent through fostering linkages among survey data managers in the region. The Association will also be in a position to support the establishment of data management facilities on the continent. At this stage it appears that these will be housed in the NSOs in African countries, as it is to these organisations that the financial and technical support is being directed. The formation of a group of dedicated practitioners in the field can serve to highlight the need for co-ordinated microdata curation in Africa. The initiation of a network of survey data managers in Africa represents the first step towards such collaboration.

*Contact: Lynn Woolfrey, Data Manager, DataFirst Resource Centre, University of Cape Town, South Africa. email: Lynn.Woolfrey@uct.ac.za.

Footnotes

${ }^{1}$ AASDA Constitution, 2008.

${ }^{2}$ http://www.mfdr.org/documents/MarrakechActionPlanfor Statistics.pdf

${ }^{3}$ IHSN website: http://www.surveynetwork.org

${ }^{4}$ IHSN website: http://www.surveynetwork.org. See also the ADP Website at http://www.surveynetwork.org/adp.

${ }^{5}$ ADP website: http://www.surveynetwork.org/adp.

${ }^{6}$ DataFirst OECD Contract, 2008.

${ }^{7}$ Tomas Bernardo, Mozambique Instituto Nacional de Estadistica, at the AASDA meeting, 2008.

${ }^{8}$ Olivier Dupriez, IHSN, 2008.

${ }^{9}$ Information from Olivier Dupriez, IHSN, 2008.

${ }^{10}$ IASSIST notes and discussions with Yakob Mudesir, Ethiopian Central Statistical Agency.

${ }^{11}$ The South African Data Archive (SADA) and DataFirst, both based in South Africa.

${ }^{12}$ These included the NSOs of Cameroon, Ethiopia, Gambia, Ghana, Liberia, Mali, Mozambique, Niger,
Nigeria, South Africa and Uganda.

${ }^{13}$ Representatives from the IHSN present at the meeting included staff from the UK Department for International Development (DFID), the PARIS21 Secretariat at OECD, and the World Bank.

${ }^{14}$ AFRISTAT is an umbrella body supporting statistical development in Francophone Africa.

${ }^{15}$ AASDA minutes, 2008.

${ }^{16}$ AASDA website: http://www.aasda.net. 